\title{
A note on recent surveys for right whales in the southeastern Bering Sea
}

\author{
R.G. LeDuc, W.L. Perryman, J.W. Gilpatrick, Jr., J. Hyde, C. Stinchcomb, J.V. Carretta and R.L. Brownell, Jr. \\ Southwest Fisheries Science Center, PO Box 271, La Jolla, CA 92038, USA \\ Contacte-mail: Rick.LeDuc@noaa.gov
}

\begin{abstract}
Research vessel and aerial platforms were used between 1997 and 2000 to collect genetic and photographic data from a small population of right whales that summers in the southeastern Bering Sea. Totals of 11 and six unique individuals were identified using photographic and genetic methods, respectively. Single matches between years occurred using both methods, and all genetic samples turned out to be from male whales. Long-term research is needed to estimate the size of this population and to determine what threats the whales may be facing.

KEYWORDS: NORTH PACIFIC RIGHT WHALE; SURVEY-AERIAL; SURVEY-VESSEL; GENETICS; PHOTOIDENTIFICATION
\end{abstract}

\section{INTRODUCTION}

Brownell et al. (2001) review $20^{\text {th }}$ century records of North Pacific right whales (Eubalaena japonica). There are thought to be at least two populations of this species, one in the western Pacific and the other in the east. The latter is one of the most endangered baleen whale populations in the world (Clapham et al., 1999). Until recently, the unpredictable nature and low number of right whale sightings in the eastern North Pacific has precluded any attempts at directed research on their status and biology. However, the discovery of a small number of animals that regularly occur in the southeastern Bering Sea (Goddard and Rugh, 1998; Tynan, 1998) has allowed us to initiate a research program aimed at characterising the remnants of this once-abundant population. This note presents the initial findings using biopsy samples and vertical aerial photographs that have been collected from these whales.

\section{SIGHTINGS}

\section{Ship surveys}

Tynan (1998) reported that on 20 July 1997, a group of at least five right whales (only three individuals were genetically identified from six biopsy samples; details given below) was sighted during a cetacean survey from the R/V Miller Freeman in the southeastern Bering Sea $\left(57^{\circ} 08^{\prime} \mathrm{N}\right.$, $\left.162^{\circ} 50^{\prime} \mathrm{W}\right)$. Based on this sighting and other opportunistic sightings during the 1990s in the southeastern Bering Sea (see Goddard and Rugh, 1998), the Southwest Fisheries Science Center (SWFSC) initiated a research program directed at right whales in this area using aerial (1998, 1999 and 2000) and vessel (1999 only) platforms. The locations of all right whales sighted during this research are presented in Fig. 1. During the July 1999 cruise conducted from the US Coast Guard vessel Sweetbrier, there were four sightings (total five whales). Biopsy samples were collected during both the 1997 and 1999 shipboard sightings (six and five samples, respectively).

\section{Aerial surveys}

Aerial surveys of the southeastern Bering Sea were conducted during July of 1998, 1999 and 2000 (methods given in Perryman et al., 1999). In 1998, there were three sightings of single right whales and a single sighting of a pair. In 1999, a single right whale was seen from the air in addition to the five whales mentioned above for the concurrent vessel survey. In 2000, there were five sightings (total 13 animals). Whenever conditions allowed, vertical aerial photographs were taken of right whales with a $127 \mathrm{~mm}$ format image motion compensated reconnaissance camera. As each photograph was taken, a data acquisition system recorded time, position and a radar altimeter reading.

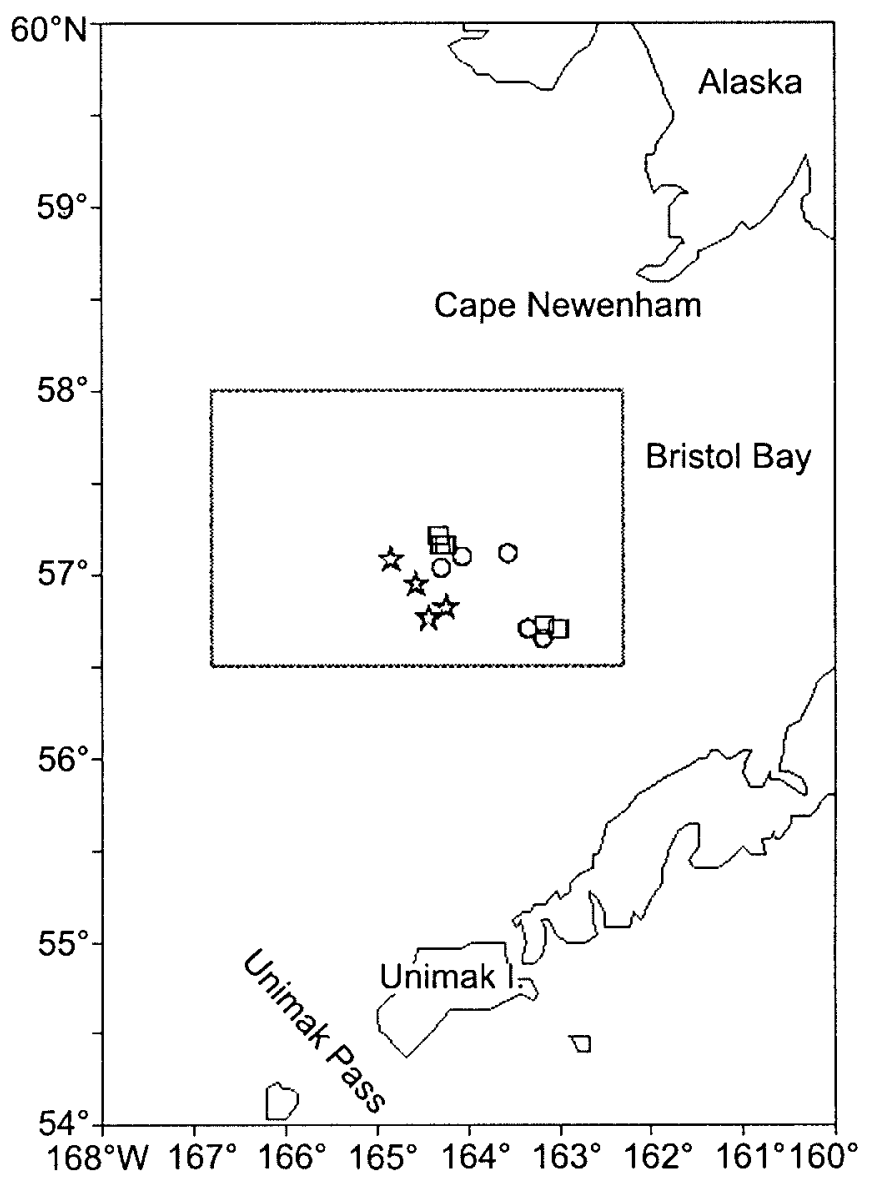

Fig. 1. Observations of right whales in the southeastern Bering Sea Key: is $=1998$ right whale sightings (4 sightings totalling 5 whales); $\bigcirc=1999$ sightings ( 5 sightings totalling 6 whales); $\square=$ 2000 sightings (5 sightings totalling 13 whales). Box represents boundaries of area surveyed by ship and aircraft. 
Altimetry data were calibrated by comparing recorded altitude readings with altitude calculated from aerial photographs of known-sized targets. Individual right whales were identified by callosity patterns on their rostra and added to the catalogue established and maintained at the SWFSC, a catalogue that also includes photographs from past opportunistic sightings from the eastern Pacific. Whenever possible, body lengths were calculated from the vertical aerial photographs.

\section{GENETIC ANALYSES}

DNA was extracted from all samples at the SWFSC, using standard protocols. A $400 \mathrm{bp}$ region of the mitchondrial control region was amplified and sequenced; some (1997 samples only) of these data were published in Rosenbaum et al. (2000) as part of a study of worldwide right whale genetic variation. In addition to the sequence data, each sample was typed for 15 microsatellite loci (Table 1).

Table 1

Microsatellite markers used in this study. Although primer pairs for each marker were as given in the cited papers, reaction conditions were altered for this study; details are available from the authors.

\begin{tabular}{ll}
\hline Microsatellite marker & Reference \\
\hline EV1, EV5, EV14, EV30, EV37, EV94 & Valsecchi and Amos (1996) \\
GATA028, GATA053, GATA098, GATA417 & Palsbøll et al. (1997) \\
DlrFCB5, DlrFCB17 & Buchanan et al. (1996) \\
GT023, GT101 & Bérubé et al. (2000) \\
SW19 & Richard et al. (1996) \\
\hline
\end{tabular}

Of the 15 markers, two (GATA053 and EV30) were monomorphic and only two alleles were represented in each of four other markers (GT023, EV5, EV14 and EV94). There was one marker (GATA417) with three alleles, three (EV1, GATA098 and EV37) with four alleles, four (GT101, SW19, GATA028 and DlrFCB17) with five and one (DlrFCB5) with six.

The sex of each individual was determined by co-amplification of segments of the $\mathrm{X}$ - and Y-chromosome-linked zinc-finger gene with a segment of the Y-chromosome-specific SRY gene ${ }^{1}$. In this method, amplification of the zinc-finger segments acts as a positive control for the PCR conditions, with successful amplification of the SRY segment serving as an indicator of the male genotype.

On the basis of the genotypes, it was found that a number of individuals had been sampled more than once: the six samples from 1997 represented three individuals (one animal was sampled twice and another three times) and the five samples from 1999 represented four individuals. In addition, one of the animals was sampled in both years, bringing the total number of individuals represented by the 11 samples to six. Rosenbaum et al. (2000) reported a sample size of five for North Pacific tissue samples from 1997. This was the number of individuals originally inferred to be represented by the six samples from 1997 (instead of three as reported here). This discrepancy resulted from premature conclusions drawn from preliminary microsatellite data by the SWFSC and provided to Rosenbaum et al. The analysis and results presented in

1 Rosenberg, A. and Mesnick, S.L. Unpublished. Protocol for the determination of gender. Contact author RGL.
Rosenbaum et al. (2000) are not affected by this change in sample size. As reported in Rosenbaum et al. (2000), the sample set contained two mitochondrial haplotypes. One haplotype occurred in a single individual (the three duplicate samples from 1997) and another in all other individuals, including all of the 1999 samples.

All of the sampled individuals were male.

\section{PHOTOGRAPHIC STUDIES}

Of all the whales photographed, there were three each from 1998 and 1999 and seven from 2000 for which the photographs were adequate for individual identification. Amongst these, the only resighting was a single individual seen in all three years. Thus a total of 11 individuals could be added to the photo-identification catalogue.

Body lengths from 12 animals were determined from the vertical aerial photographs. This total differs from the number of individuals added to the catalogue because some of the identified animals could not be accurately measured due to the position of their bodies in the photographs whilst some of the animals that could be measured could not be individually identified because poor lighting or water obscured their callosity patterns. The total lengths of the 12 whales ranged from 14.7 to $17.6 \mathrm{~m}$. Based on the examination of 23 North Pacific right whales, Omura et al. (1983) and Klumov (1962) estimated that females and males can be sexually mature after about $15 \mathrm{~m}$ in total length. Therefore, regardless of sex, all the right whales we measured may have been sexually mature except perhaps the three smallest ones (14.7, 15.1 and 15.2m).

\section{DISCUSSION}

The results of the present study do little to alleviate concerns about eastern North Pacific right whales. Even with these limited data, the population is clearly the most endangered in US waters. The sightings were clustered within a relatively small section of our survey area (Fig. 1), in spite of the cumulative search effort of over $15,400 \mathrm{~km}$ of aerial tracklines and over $1,400 \mathrm{~km}$ of vessel tracklines across that area. The fact that there were instances of genetic and photographic resampling of individuals between years even with such small datasets supports the idea that the population is critically small (Brownell et al., 2001). In addition, the detection of only two haplotypes may mean that genetic diversity has already been severely compromised. Of particular concern is that all of the biopsied individuals from both years were male; barring geographic segregation by sex on the summering grounds (or some behavioural characteristic of males that makes them easier to biopsy) this raises the possibility that females are few or lacking.

However, any inferences must be tempered by a consideration of the limitations of the data. The number of individuals for which the sex has been determined is only about half of the minimum number of individuals determined from the catalogue, which itself is not a complete representation of the population in the Bering Sea (new individuals still comprised all but one of the photographs taken in 2000). Furthermore, eastern North Pacific right whales seen south of the Bering Sea for which there are adequate photographs (at least four animals) can be reliably ruled out as matches to those photographed in the Bering Sea. 
The small sample size makes it premature to make any other inferences about the characteristics of this population, such as levels of heterozygosity or the degree of relatedness among individuals. Similarly, a reliable population estimate based on mark-recapture is not possible with so few samples. Such questions can only be addressed by the continuation of biopsy and photographic efforts until an adequate collection has been built up. However, the present genetic results do suggest that there is sufficient variability to establish a catalogue of individual whales based on DNA fingerprints, a valuable complement to the photo-ID catalogue. Obviously, there is also a dire need for other information about North Pacific right whales. For example, their abundance in the southeastern Bering Sea cannot be reliably estimated from the present data, their seasonal movements and distribution are almost completely unknown and potential anthropogenic threats to their survival are yet to be determined.

\section{ACKNOWLEDGEMENTS}

The collection of biopsy samples from right whales in the southeast Bering Sea in 1997 was supported by a grant to C. Tynan by the Office of Protected Resources, NOAA, Recover Protected Species Program. All other research discussed here was supported by grants from the same agency to the SWFSC. We would also like to acknowledge the cooperation and skill of the command and crews of the R/V Miller Freeman and the USCGC Sweetbrier during the 1997 and 1999 survey cruises, respectively. Aerial surveys were conducted with the services of Commander Northwest Ltd., and were successful largely due to the abilities of the pilot, Dave Weintraub. We would like to thank the numerous shipboard and aerial observers and scientists who gathered all the data. One in particular deserves special mention: Bob Pitman, who collected all the biopsies discussed here and was indispensable in the field.

\section{REFERENCES}

Bérubé, M., Jørgensen, H., McEwing, R. and Palsbøll, P.J. 2000. Polymorphic di-nucleotide microsatellite loci isolated from the humpback whale, Megaptera novaeangliae. Mol. Ecol. 9:2,181-3.

Brownell, R.L., Clapham, P.J., Miyashita, T. and Kasuya, T. 2001. Conservation status of North Pacific right whales. J. Cetacean Res. Manage. (special issue) 2:269-86.

Buchanan, F.C., Friesen, M.K., Littlejohn, R.P. and Clayton, J.W. 1996. Microsatellites from the beluga whale Delphinapterus leucas. Mol. Ecol. 5:571-5.

Clapham, P.J., Young, S.B. and Brownell, R.L. 1999. Baleen whales: conservation issues and the status of the most endangered populations. Mammal Rev. 29:35-60.

Goddard, P.D. and Rugh, D.J. 1998. A group of right whales seen in the Bering Sea in July 1996. Mar. Mammal Sci. 14(2):344-9.

Klumov, S.K. 1962. Gladkie (Yaponskie) kity Tikhogo Okeana [The right whales in the Pacific Ocean]. Tr. Inst. Okeanol. Akad. Nauk SSSR 58:202-97. [In Russian].

Palsbøll, P.J., Bérubé, M., Larsen, A.H. and Jørgensen, H. 1997. Primers for the amplification of tri- and tetramer microsatellite loci in baleen whales. Mol. Ecol. 6:893-5.

Perryman, W.L., LeDuc, R. and Brownell, R.L., Jr. 1999. Progress report on eastern North Pacific right whale research during July 1998. Paper SC/51/CAWS36 presented to the IWC Scientific Committee, May 1999, Grenada, WI (unpublished). 10pp. [Paper available from the Office of this Journal].

Reeves, R.R., Kraus, S. and Turnbull, P. 1983. Right whale refuge? Nat. Hist. 92(4):40-5.

Richard, K.R., Whitehead, H. and Wright, J.M. 1996. Polymorphic microsatellites from sperm whales and their use in the genetic identification of individuals from naturally sloughed pieces of skin. Mol. Ecol. 5:313-5.

Rosenbaum, H.C., Brownell Jr, R.L., Brown, M.W., Schaeff, C., Portway, V., White, B.N., Malik, S., Pastene, L.A., Patenaude, N.J., Baker, C.S., Goto, M., Best, P.B., Clapham, P.J., Hamilton, P., Moore, M., Payne, R., Rowntree, V., Tynan, C.T. and DeSalle, R. 2000. Worldwide genetic differentiation of Eubalaena: questioning the number of right whale species. Mol. Ecol. 9(11):1793-802.

Tynan, C.T. 1998. Critical habitat and abundance estimation or right whales in the southeast Bering Sea. Paper SC/50/CAWS18 presented to the IWC Scientific Committee, April 1998 (unpublished). 9pp. [Paper available from the Office of this Journal].

Valsecchi, E. and Amos, W. 1996. Microsatellite markers for the study of cetacean populations. Mol. Ecol. 5:151-6. 